RASĀYAN J. Chem.

Vol. 13 | No. 4 |2646-2652| October - December | 2020 ISSN: 0974-1496 | e-ISSN: 0976-0083 | CODEN: RJCABP

\title{
KINETICS OF EXTRACTION OF INORGANIC CHLORIDES FROM LEAD PRODUCTION SLAGS IN THE PRESENCE OF DISTILLER LIQUID
}

\author{
D.T.Pazylova ${ }^{1, *}$, V.M. Shevko ${ }^{2}$, A.S.Tleuov ${ }^{3}$, B.A. Lavrov ${ }^{4}$, N.S. Saidullayeva ${ }^{5}$ \\ and A.S.Abzhanova ${ }^{6}$ \\ ${ }^{1,3}$ M.Auezov South Kazakhstan University/ Department of Technology of Inorganic \\ Substances, Tauke Khan av.5, 160012, Kazakhstan \\ ${ }^{2,6}$ M. Auezov South Kazakhstan University/ Department of Metallurgy, Tauke Khan av.5, \\ 160012, Kazakhstan \\ ${ }^{4}$ St. Petersburg State Technological Institute (Technical University)/Department of General \\ Chemical Technology and Catalysis 190013, Russia \\ ${ }^{5}$ M. Auezov South Kazakhstan University/ Department of Physics, Tauke Khan av.5, 160012, \\ Kazakhstan \\ *E-mail: danapazyl@mail.ru
}

\begin{abstract}
The article presents the results of a study of the kinetics of extraction of non-ferrous metals in the form of inorganic chlorides from lead fusing slags in the presence of a distiller's liquid. It is established that the maximum degree of chloride distillation of non-ferrous metals from the fusing slag (lead by $92.2 \%$, copper-89.2\%, zinc $92.0 \%$ ) is observed at a temperature of $1000^{\circ} \mathrm{C}$ for 90 minutes. It was determined that an increase in the degree of chloride distillation of copper and lead is accompanied by a decrease in the $E_{\text {ap }}$ for copper from 126 to $54 \mathrm{~kJ} / \mathrm{mol}$ and lead from 128 to $88 \mathrm{~kJ} / \mathrm{mol}$. Chloride distillation of copper at the beginning of the process proceeds in the kinetic mode, at the end in the transition, and lead - in the kinetic model. The life span of the generation period of copper chloride distillation is $140 \mathrm{~kJ} / \mathrm{mol}$, and lead- $162 \mathrm{~kJ} / \mathrm{mol}$. Zinc chloride distillation takes place in a transient mode and is characterized by $\mathrm{E}_{\mathrm{ap}} 58 \mathrm{~kJ} / \mathrm{mol}$. Intensification of metal chloride distillation from slags is possible due to an increase in temperature.

Keywords: Fuming Slag, Distilled Liquid, Nonferrous Metal Chlorides, Kinetics, Apparent Activation Energy, Process Area.
\end{abstract}

(C) RASĀYAN. All rights reserved

\section{INTRODUCTION}

In modern conditions, when the issue of protecting the environment from harmful industrial influences has become particularly acute all over the world, research in the field of processing various wastes, in particular waste from the production of calcinated soda-distiller liquid, is of greater importance. The main components of the distiller liquid are calcium chloride $\left(\mathrm{CaCl} 2,118-125 \mathrm{~g} / \mathrm{m}^{3}\right)$ and sodium chloride $\left(\mathrm{NaCl}, 50-80 \mathrm{~g} / \mathrm{m}^{3}\right)$.Several new methods of distiller liquid processing have been developed: production of calcium-magnesium phosphates, ${ }^{1}$ gypsum, ${ }^{2}$ flue gas neutralization, ${ }^{3}$ productions of calcium carbonate and hydrogen chloride ${ }^{4}$, ammonium chloride, ${ }^{5}$ anhydrous calcium peroxide. ${ }^{6}$ The applied technologies for processing distiller liquid do not solve the problem completely, due to the large volume of waste generated, for example, in Russia, the Czech Republic, China, France and Germany, dumping is performed all year round. ${ }^{7}$ We suggest using a distiller liquid to extract non-ferrous metals from fusing slags in the form of inorganic chlorides. ${ }^{8}$ Despite the positive results of this method, the kinetics of chloride distillation of metals from fusing slags in the presence of a distiller liquid has not yet been studied. The purpose of the work is to determine the kinetic regularities of chloride distillation of copper, zinc, and lead from the blown slags of mine lead smelting.

Rasayan J. Chem., 13(4), 2646-2652(2020)

http://dx.doi.org/10.31788/ RJC.2020.1345862 
RASĀYAN J. Chem.

Vol. 13 | No. 4 |2646-2652| October - December | 2020

\section{Materials and Methods}

\section{EXPERIMENTAL}

The research was carried out on a laboratory installation, the scheme of which is shown in figure1. the Installation provided for the horizontal movement of air and gas in the reaction space. The installation consists of a tubular furnace with carborundum heaters. In the inner space of the furnace, there is a quartz tube (2) with an alundumboat (3) the process Temperature was controlled by a thermocouple PP-1 (4), working together with a potentiometer KSP-4 (5). Control of the airflow supplied by the compressor (Mateus, Italy) was carried out by a rheometer (6). The voltage to the furnace was supplied from the transformer RNO-250. Non-ferrous metal chlorides were detected in flasks filled with $\mathrm{Ca}(\mathrm{OH})_{2}$ solution $(7,8)$. The boat with the granulated charge was loaded into the quartz tube of the furnace, which was preheated to the required temperature.

After the experiments, the firing products were weighed and analyzed for non-ferrous metals using the volumetric method or the AAS- $1 \mathrm{~N}$ device. The relative error of the experiments did not exceed $3-4 \%$. The degree of chloride distillation of non-ferrous metals was determined by the ratio of the mass of the ignited metal to the mass of the metal in the loaded charge.

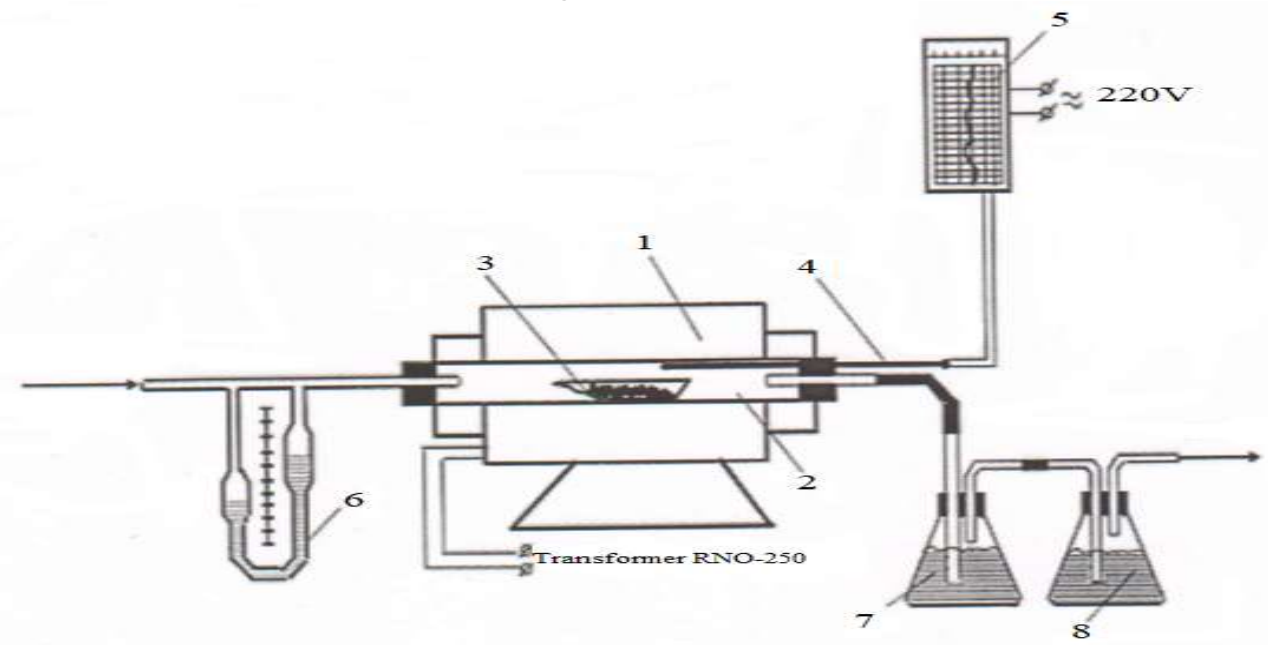

1-tube furnace; 2-quartz tube; 3-boat with a charge; 4-thermocouplePP-1; 5-potentiometer KSP-4; 6-rheometer; 7,8bottles filled with a $\mathrm{Ca}(\mathrm{OH})_{2}$ solution

Fig.-1: The Installation for Study of Metal Chloride Sublimation Kinetics

The composition of the fuming slag applied for the research is shown in Fig.-2.

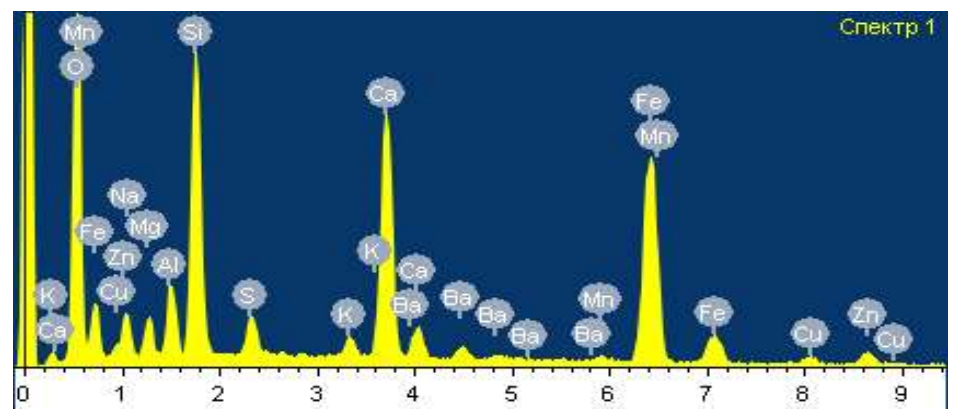

\begin{tabular}{|c|c|c|c|c|c|c|c|c|c|c|c|c|c|}
\hline Element & $\mathrm{O}$ & $\mathrm{Na}$ & $\mathrm{Mg}$ & $\mathrm{Al}$ & $\mathrm{Si}$ & $\mathrm{S}$ & $\mathrm{K}$ & $\mathrm{Ca}$ & $\mathrm{Mn}$ & $\mathrm{Fe}$ & $\mathrm{Cu}$ & $\mathrm{Zn}$ & $\mathrm{Pb}^{*}$ \\
\hline Mass \% & $\stackrel{m}{\vec{n}}$ & $\stackrel{2}{g}$ & $\stackrel{\infty}{a}$ & $\underset{\stackrel{i}{i}}{\stackrel{\nabla}{ }}$ & $\begin{array}{l}\hat{6} \\
0 \\
0\end{array}$ & $\stackrel{n}{\text { nf }}$ & $\begin{array}{l}+ \\
\infty \\
0\end{array}$ & $\stackrel{\&}{\underset{\exists}{\exists}}$ & $\bar{n}$ & 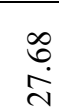 & $\stackrel{\infty}{\circ}$ & $\stackrel{\vec{r}}{\dot{m}}$ & $\stackrel{m}{0}$ \\
\hline
\end{tabular}

*The lead content in the slag was determined on the device AAS-1N, was $0.3 \%$.

Fig.-2: The Elemental Composition of the Slag Determined by the Scanning Electron Microscopy Technique 
RASĀYAN J. Chem.

Vol. 13 | No. 4 |2646-2652| October - December | 2020

The composition of the dry residue of the distilled liquid is represented in Fig.-3.

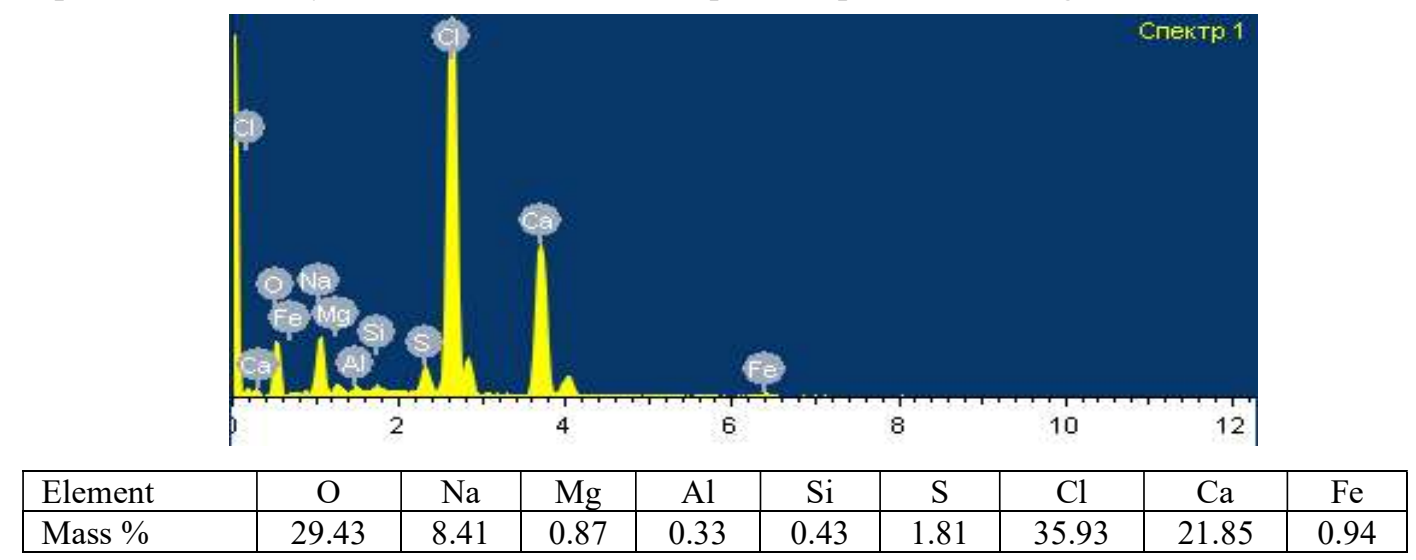

Fig.-3: The Elemental Composition of the Dry Residue of the Distilled Liquid Determined by the Scanning Electron Microscopy Technique

The weight of the distilled liquid's dry residue (mass \%: $61.0 \mathrm{CaCl}_{2} ; 29.7 \mathrm{NaCl} ; 4.7 \mathrm{Ca}(\mathrm{OH})_{2} ; 1.3 \mathrm{CaSO}_{4}$; $0.2 \mathrm{SiO}_{2} ; 3.0 \mathrm{CaCO}_{3} ; 0.1$ others) was $10 \%$ of the slag weight. Before the experiment, the slag was ground to a fraction of less than $0.1-0.15 \mathrm{~mm}$. Then the slag was mixed with betonies clay and the distilled liquid; the mixture obtained was pelletized. The wet granules (8-10\% of water) were dried at a temperature of $200-260^{\circ} \mathrm{C}$ for 30 minutes. The top drying limit was bounded to the possibility of $\mathrm{CaCl}_{2}$ decomposition according to the reaction $\mathrm{CaCl}_{2}+\mathrm{H}_{2} \mathrm{O} \rightarrow 2 \mathrm{HCl}+\mathrm{CaO}$, that leads to chlorine losses.

\section{RESULTS AND DISCUSSION}

Figure-4 contains the information about the temperature effect on the chloride sublimation of copper and lead from the fuming slag.
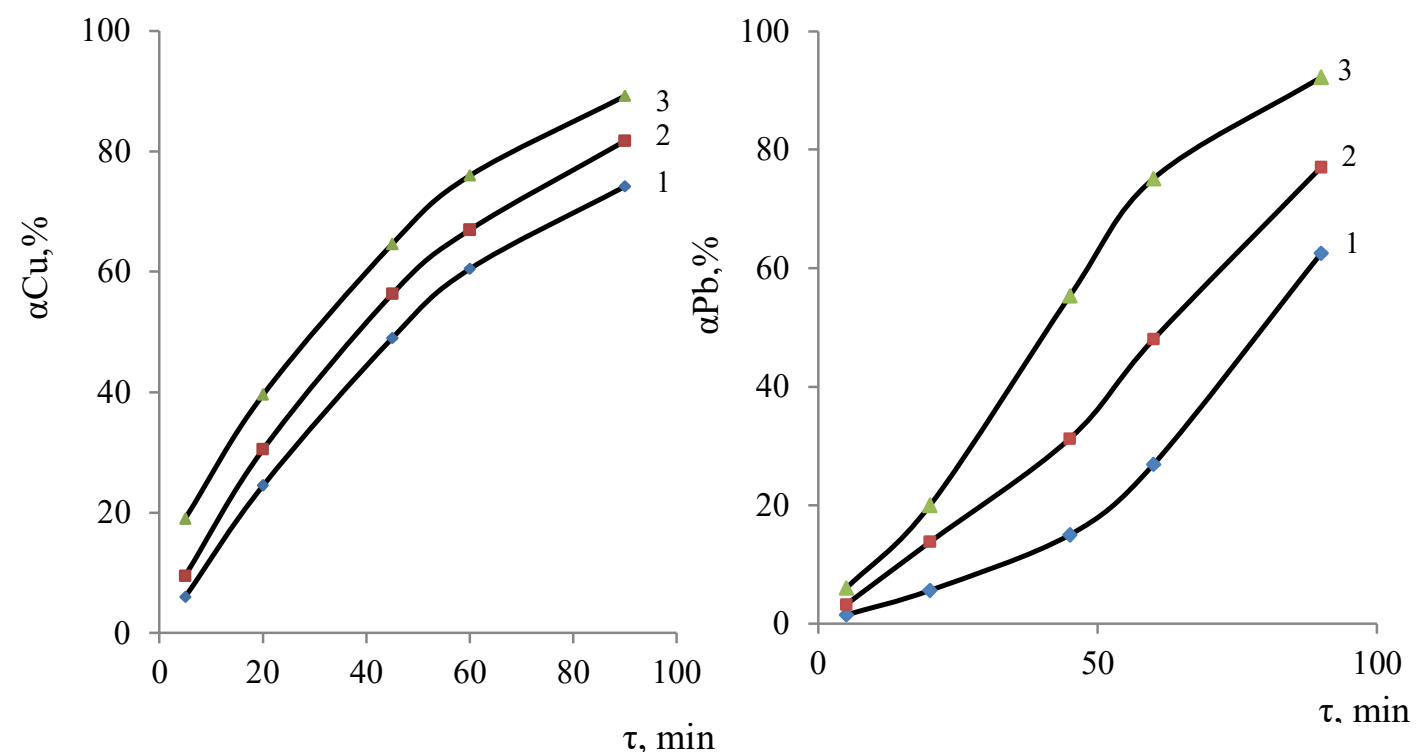

$\tau, \min$

$1-900^{\circ} \mathrm{C}, 2-950^{\circ} \mathrm{C}, 3-1000^{\circ} \mathrm{C}$

Fig.-4: Temperature and Time Effect on the Copper and Lead Chloride Sublimation From the Fuming Slag

The results point to the fact that the copper and lead chloride sublimation increases with an increase in the experiment temperature and duration. The maximum copper and lead chloride sublimation degree from the fuming slag was reached at a temperature of $1000^{\circ} \mathrm{C}$ and duration of 90 minutes (for copper $-89,2 \%$, 
RASĀYAN J. Chem.

Vol. 13 | No. 4 |2646-2652| October - December | 2020

for lead - 92,2\%). To determine the apparent activation energy $\left(E_{a p}\right)$ we used the method described in. ${ }^{9}$ Following this method the calculation of $E_{a p}$ is implemented based on the time necessary for the achievement of the same process level at different temperatures, $\tau\left(\alpha_{i}\right)$. The time of achievement of several levels of copper and lead chloride sublimation is shown in Table-1.

Table-1:Time of Achievement (min) of Several Levels of Copper and Lead Chloride Sublimation $(\alpha, \%)$ in the Temperature Interval of $900-1000^{\circ} \mathrm{C}$

\begin{tabular}{l|l|l|l|l|l|l}
\hline \multirow{2}{*}{$\alpha, \%$} & \multicolumn{2}{|c|}{$900^{\circ} \mathrm{C}$} & \multicolumn{2}{c|}{$950^{\circ} \mathrm{C}$} & \multicolumn{2}{c}{$1000^{\circ} \mathrm{C}$} \\
\cline { 2 - 7 } & $\mathrm{Cu}$ & $\mathrm{Pb}$ & $\mathrm{Cu}$ & $\mathrm{Pb}$ & $\mathrm{Cu}$ & $\mathrm{Pb}$ \\
\hline 20 & 17 & 54 & 10 & 30 & 7 & 20 \\
\hline 30 & 25 & 64 & 20 & 43 & 13 & 35 \\
\hline 40 & 35 & 73 & 28 & 54 & 20 & 33 \\
\hline 50 & 45 & 80 & 38 & 63 & 30 & 40 \\
\hline 60 & & 81 & & 72 & & 47 \\
\hline 70 & 77 & & 65 & & 50 & \\
\hline
\end{tabular}

The $\lg \tau\left(\alpha_{i}\right)-1 /$ T curves for several levels of copper and lead chloride sublimation are represented in Fig.5 and 6. These curves allowed us to determine values of the tangent of the inclination angle of each the straight to the X-axis, $\left(\operatorname{tg} \varphi_{i}\right)$ for several levels of the copper and lead chloride sublimation.

1

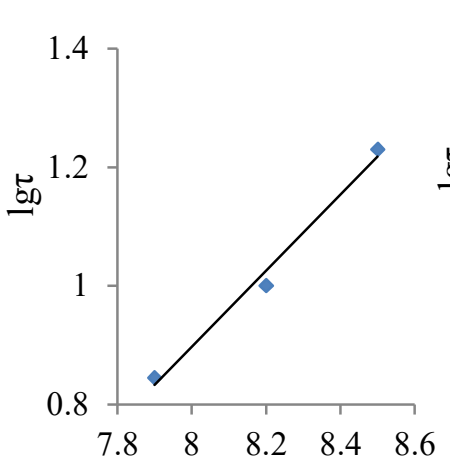

$(1 / \mathrm{T}) \cdot 10^{4}$
2

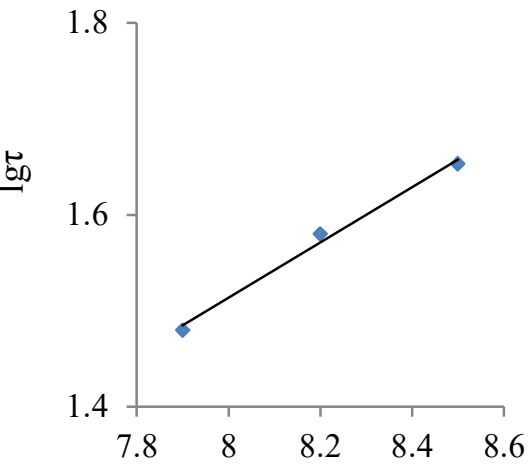

$(1 / \mathrm{T}) \cdot 10^{4}$
3

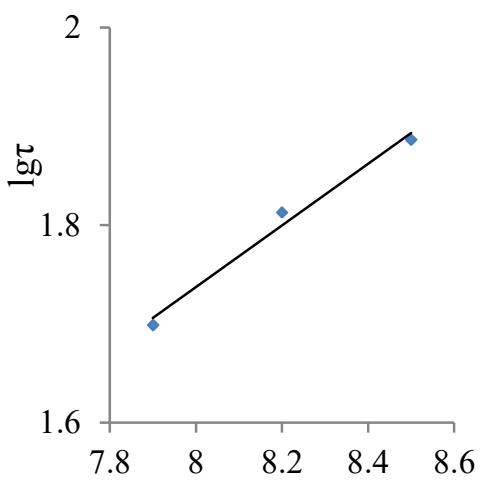

$(1 / \mathrm{T}) \cdot 10^{4}$

$$
1-\alpha_{\mathrm{ch}}=20 \%, 2-\alpha_{\mathrm{ch}}=50 \%, 3-\alpha_{\mathrm{ch}}=70 \%
$$

Fig.-5: The $\lg \tau\left(\alpha_{\mathrm{i}}\right)-1 / \mathrm{T}$ Curve for Several Levels of the Copper Chloride Sublimation

The apparent activation energy, $E_{a p}$, for different levels of the copper and lead chloride sublimation from the fuming slag was calculated using the following equation:

$$
\mathrm{E}_{a p}=\operatorname{tg} \varphi \cdot 19,169
$$

The calculated $\mathrm{E}_{\mathrm{ap}}$ values are represented in Table-2.

\begin{tabular}{|c|c|c|c|c|c|c|c|}
\hline \multirow[t]{2}{*}{$\alpha, \%$} & \multicolumn{2}{|c|}{20} & 40 & \multicolumn{2}{|c|}{50} & 60 & 70 \\
\hline & $\mathrm{Cu}$ & $\mathrm{Pb}$ & $\mathrm{Pb}$ & $\mathrm{Cu}$ & $\mathrm{Pb}$ & $\mathrm{Pb}$ & $\mathrm{Cu}$ \\
\hline $\mathrm{E}_{\mathrm{ap}}, \mathrm{kJ} / \mathrm{mol}$ & 126 & 138 & 109 & 72 & 96 & 88 & 54 \\
\hline
\end{tabular}

Table-2: Values of $E_{\text {ap }}$ for Different Levels of the Copper and Lead Chloride Sublimation

It is obvious, that at the increase in the copper and lead chloride sublimation degree the apparent activation energy decreases (for copper from 126 to $54 \mathrm{~kJ} / \mathrm{mol}$, for the lead from 138 to $88 \mathrm{~kJ} / \mathrm{mol}$ ). According to, ${ }^{10,11}$ it is possible to assume, that at the beginning the copper chloride sublimation process occurs in the kinetic regime, and then, at $\alpha_{\mathrm{ch}}=70 \%$ - on the border of kinetic and transient regimes, and 
RASĀYAN J. Chem.

Vol. 13 | No. 4 |2646-2652| October - December | 2020

for the lead at $\alpha_{\mathrm{ch}}=20-60 \%$ - in the kinetic area. The dependence $\mathrm{E}_{a p}=f(\alpha)$ (Fig.-7) for chloride sublimation of copper and lead was found using the data represented in Table-2.
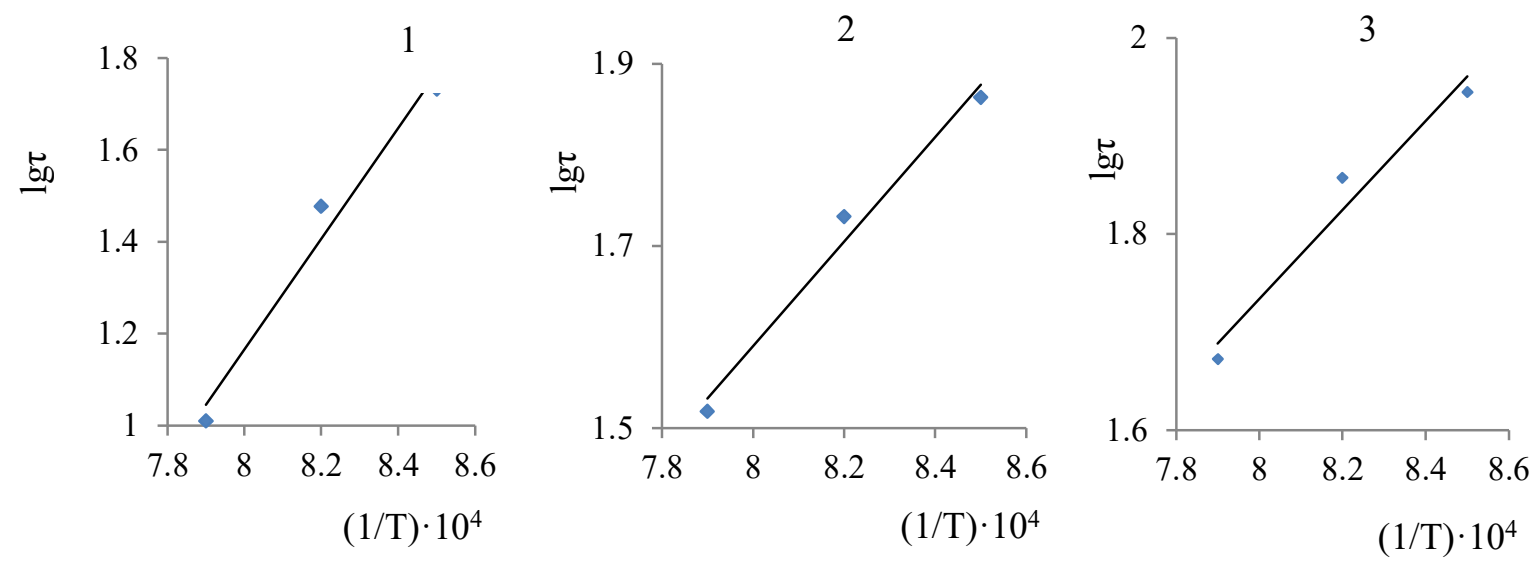

$1-\alpha_{\mathrm{ch}}=20 \%, 2-\alpha_{\mathrm{ch}}=40 \%, 3-\alpha_{\mathrm{ch}}=60 \%$

Fig.-6: The $\lg \tau\left(\alpha_{\mathrm{i}}\right)-1 / \mathrm{T}$ Curve for Several Levels of the Lead Chloride Sublimation

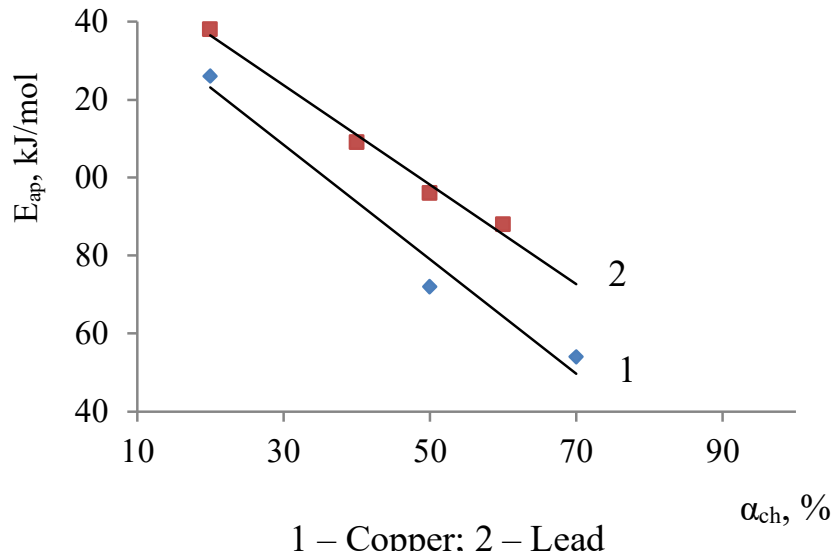

Fig.-7: Dependence of the $\mathrm{E}_{a p}$ Activation Energy on the Degree of Chloride Distillation of Copper and Lead

The dependence of $\mathrm{E}_{a p}=f(\alpha)$ for copper and lead can be described by the equations:

$$
\begin{aligned}
& \mathrm{E}_{a p}(\mathrm{Cu})=140.04-1.295 \alpha_{c h} \\
& \mathrm{E}_{a p}(P b)=162.03-1.277 \alpha_{c h}
\end{aligned}
$$

As follows from equations (2) and (3), at the initiation of the copper chloride sublimation process, when $\alpha$ approximates to zero, $\mathrm{E}_{a p}$ makes $139.8 \mathrm{~kJ} / \mathrm{mol}$, the similar value for lead is $162.03 \mathrm{~kJ} / \mathrm{mol}$. To determine the regime of the copper chloride sublimation from the slag after the fuming the experimental results were processed using the Pavlyuchenko equation, ${ }^{12}$ which describes the processes occurring in the kinetic regime:

$$
1-\sqrt[3]{1-\alpha}=k \cdot \tau
$$

The $1-\sqrt[3]{1-\alpha}=f(\tau)$ the curve for chloride sublimation of copper from the fuming slag is shown in Fig.-8. The tangent of the inclination angle of the straight lines to the $\mathrm{X}$-axis, $\operatorname{tg} \varphi$, was applied to determine the rate constant of the process, $\operatorname{tg} \varphi=k$ (Table-3).

Table-3: Values of $k$ for Copper and Lead Chloride Sublimation

\begin{tabular}{l|c|c|c|c}
\hline $\mathrm{T},{ }^{0} \mathrm{C}$ & $900^{0} \mathrm{C}$ & $950^{0} \mathrm{C}$ & $1000^{0} \mathrm{C}$ \\
\hline \multirow{2}{*}{$k, \min ^{-1}$} & $\mathrm{Cu}$ & 0,004 & 0,005 & 0,006 \\
\cline { 2 - 5 } & $\mathrm{Pb}$ & 0,002 & 0,003 & 0,005 \\
\hline
\end{tabular}


RASĀYAN J. Chem.

Vol. 13 | No. 4 |2646-2652| October - December | 2020

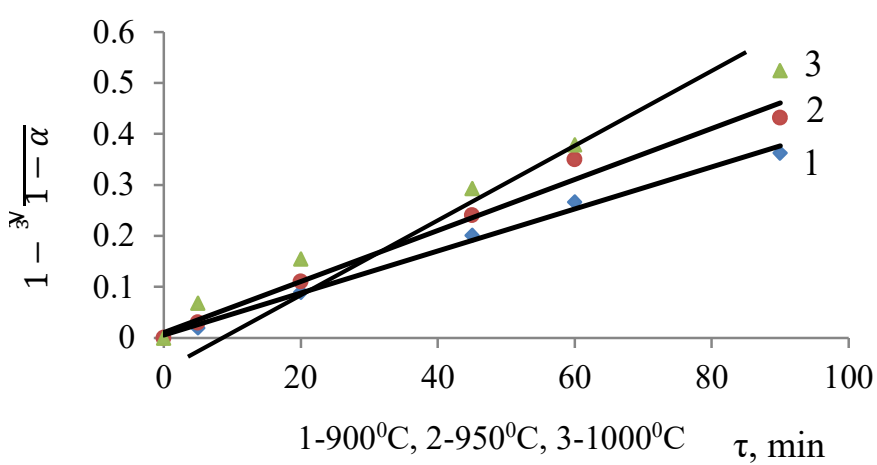

Fig.-8: The $1-\sqrt[3]{1-\alpha}=f(\tau)$ the Curve for Copper Chloride Sublimation from the Fuming Slag The $\lg k=f\left(\frac{1}{T}\right)$ curve is represented in Fig.-9.

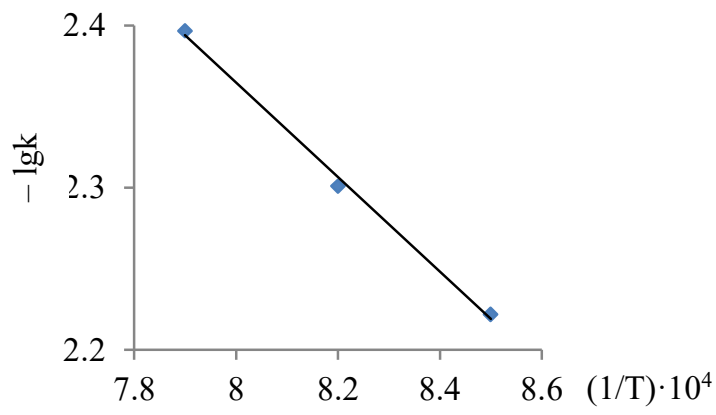

Fig.-9: Thelgk $=f\left(\frac{1}{T}\right) \cdot 10^{4}$ Curve

The tangent of the inclination angle of the straight line to the $\mathrm{X}$-axis was determined using Fig.-9. Then the apparent activation energy was calculated on formula (1): $\mathrm{E}_{\mathrm{ap}}(\mathrm{Cu})=96 \mathrm{~kJ}, \mathrm{E}_{\mathrm{ap}}(\mathrm{Pb})=191 \mathrm{~kJ}$. It is evident, that the $\mathrm{E}_{\mathrm{ap}}$ values are equal to the $\mathrm{E}_{\mathrm{ap}}$ determined previously. Therefore, the process occurs in the kinetic area.

A fragment of the temperature and time influence on the chloride sublimation of zinc from the slag is shown in Fig.-10. As is obvious from the figure, the 80-90\% chloride sublimation of zinc (the fill area of Fig.-10) occurs within $69-90$ minutes in the temperature interval of $950-1000^{\circ} \mathrm{C}$. The curve of $\lg \tau(60)=f(1 / T)$ for $60 \%$ zinc chloride sublimation degree is represented in Fig.-11.

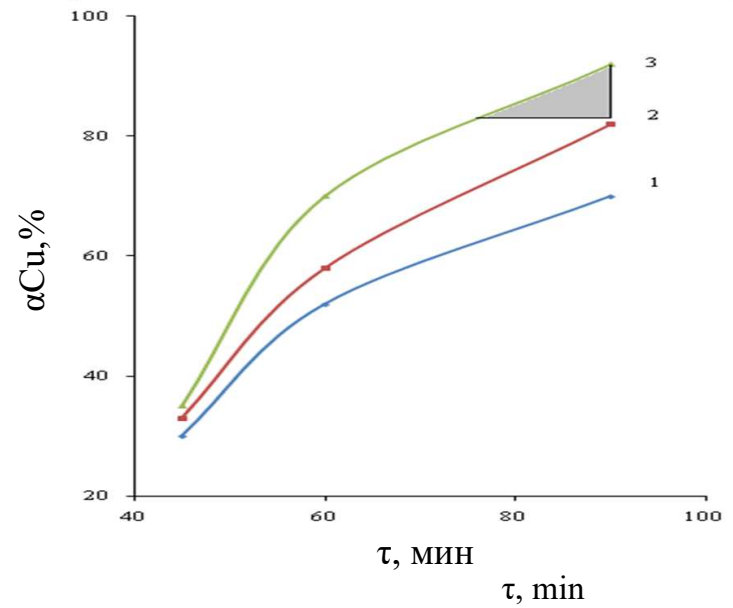

Fig.-10: Temperature and Time Effect on the Zinc Chloride Sublimation Degree from the Fuming Slag (Fragment)

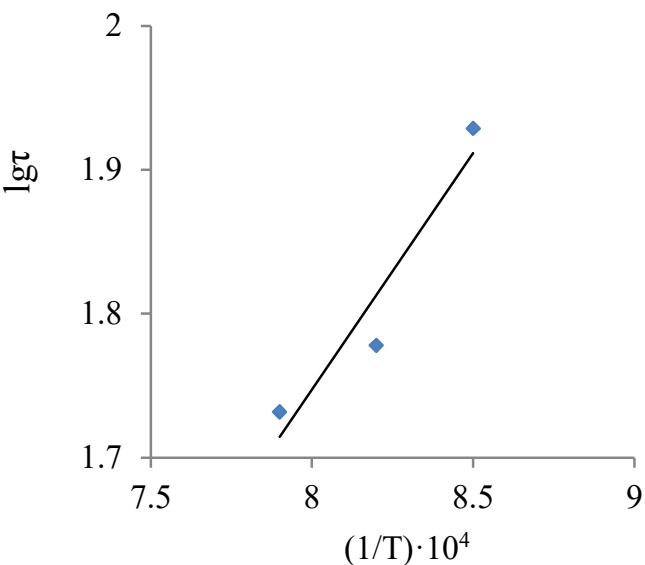

Fig. -11 :The $\lg \tau(60)=f(1 / T)$ Curve for the Chloride Sublimation of Zinc from the Fuming Slag

The apparent activation energy for chloride inetic regimes. 
RASĀYAN J. Chem.

Vol. 13 | No. 4 |2646-2652| October - December | 2020

\section{CONCLUSION}

Based on the results obtained on the kinetics of chloride distillation of non-ferrous metals from slags after fusing, the following conclusions can be drawn:

- The maximum degree of chloride distillation of non-ferrous metals from fusing slag (lead by $92.2 \%$, copper- $89.2 \%$, zinc $92 \%$ ) is observed at a temperature of $1000^{\circ} \mathrm{C}$ for 90 minutes.

- An increase in the degree of chloride distillation of copper and lead is accompanied by a decrease in the $\mathrm{E}_{\mathrm{ap}}$ for copper from 126 to $54 \mathrm{~kJ} / \mathrm{mol}$ and lead from 128 to $88 \mathrm{~kJ} / \mathrm{mol}$. Chloride distillation of copper at the beginning of the process proceeds in the kinetic mode, at the end in the transition, and lead-in the kinetic model. The age of the origin of copper chloride distillation is $140.04 \mathrm{~kJ} / \mathrm{mol}$, and lead $-162.03 \mathrm{~kJ} / \mathrm{mol}$.

- The chloride sublimation of zinc occurs in the transient regime; the $\mathrm{E}_{\mathrm{ap}}$, in this case, is $58 \mathrm{~kJ} / \mathrm{mol}$.

- Growth of the process temperature promotes intensification of the copper, lead and zinc chloride sublimation.

\section{REFERENCES}

1. R. Buczkowski, T. Kasikowski, Polish Journal of Applied Chemistry,46,113(2002).

2. T. Kasikowski, R. Buczkowski, M. Cichosz, International Journal of Production Economics, 112,980. (2008), DOI:10.1016/j.ijpe.2007.08.003

3. T. Kasikowski, R. Buczkowski, M. Cichosz, E. Lemanowska, Resources.Conservation andrecyclin, 51, 672 (2007), DOI:10.1016/j.resconrec.2006.11.009

4. Yunzhao Li, Xingfu Song, Guilan Chen, Ze Sun, Yanxia Xu, Jianguo Yu, Chemical Engineering Journal. 278,58 (2015), DOI:10.1016/j.cej.2014.12.058

5. A.A. Mukhametov, A.V. Voronin, N.B. Sadykov, A.G. Mustafin, Mukhametov A.A. Russia, Patent 2495824 (2013).

6. Ye.I. Bakhonina, I.H. Bikbulatov, A.Yu. Bakiyev, R.R. Daminev, R.R. Nasyrov, F.R. Oparina, Russia, Patent 2341449(2007).

7. M.S. Konstantinova, Ye. V. Kalinina. Herald of Perm National Research Polytechnic University. Urbanism,4, 140(2013).

8. A.S. Tleuov,V.M. Shevko, B.A. Lavrov, S.T. Tleuova., D.T Pazylova. Kazakhstan, Patent on a useful model No. 4038 (2019).

9. G.M.Voldman, A.N.Zelikman Theory of Hydrometallurgical Processes, Interment Engineering, Moscow, 264. (2003)

10. A. V. Vanyukov, V. Ya. Zaitsev, Theory of Pyrometallurgical Processes, Metallurgy, Moscow,p. 311(1973).

11. V.M. Shevko, A.D. Badikova, D.D. Amanov, G.E. Karataeva, B.A. Lavrov, Rasayan Journal of Chemistry, 11(3), 1050(2018), DOI:10.31788/RJC.2018.1132038

12. B. M. Smailov, O.K. Beisenbayev, A.S. Tleuov, A.A. Kadirbaeva, B.S. Zakirov and Mirzoyev Bahodur, Rasayan Journal of Chemistry, 13(3), 1372(2020), DOI:10.31788/RJC.2020.1335726

[RJC-5862/2020] 